\section{REPORT ON BACTERIOLOGY.}

BY HAROLD C. ERNST, A.M., M.D., (HARV.), Demonstrator of Bacteriology in the Medical School of Harvard University.

Further investigations upon malaria by Golgi ${ }^{1}$ have been made by the observation of forty cases mostly of the quartantype. Out of these forty cases but two gave negative results in the observation of the blood. In all the other cases the characteristic "Plasmodia" were found, the results being tabulated as follows:

I. Plasuodia only were found in the interior of the red blood-corpuscles in four cases.

II. Plasmodia and pigmented bodies in the red blood-corpuscles in eight cases.

III. Only pigmented bodies in the red blood-corpuscles in twenty-seven cases.

IV. Plasmodia in the red blood-corpuscles and free half-moon shaped, oval or circular bodies in one case.

In most of the cases there were also found the pigmented bodies described by Marchiafava and Celli. ${ }^{2}$ In one case the plasinodia showed amœboid movements after four and one-half hours at a temperature of $9^{\circ}$ to $10^{\circ} \mathrm{C}$. The pigmented corpuscles were also seen to have amœboid movements. Golgi considers the pigmented bodies and the plasmodia (uupigmented) to be distinct, and finds the pigmented bodies to be especially characteristic of the quartan type of fever - considering the occurrence of plasmodia in this type as a complication. The quantity of the organisms found seems to bear a distinct relationship to the severity of the attack. The condition of the pigmented bodies as seen under the microscope seems to this observer to indicate the stage of the disease, and one can prognosticate the attack by observing how near complete their growth is, as indicated by their situation in the bloodcorpuscles and amount of subdivision. These conclusions, however, are only applicable to the quartan type as yet.

\section{TUBERCLE-BACILLI.}

The question as to the positive diagnosis of this organism by the staining method of Koch-Ehrlich has received renewed attention. ${ }^{8}$ The conclusions from the results thus far obtained seeming to be that occasionally the presence of organisms in fat-bearing materials, prevents the decolorizing action of nitric acid, and that therefore there may be occasions, as in the case of smegma-bacilli, where there is an imperfect application of the staining-method, and where confusion might arise. The work is not by any means complete, however, and does not destroy the value of the usual staining method for the clinical recognition of the bacilli of tuberculosis.

\section{ULCERATIVE ENDOCARDITIS.}

Wyssokowitsch ${ }^{4}$ undertakes to produce this disease in animals by using pure culture of the organisms derived from pus in acute inflammatory conditions. The results were positive only when artificial irritation of the cardiac valve was practised. Ribbert ${ }^{6}$ succeeded

1 Sulla Infezione Malarica. Arch. per le Scienzhe Medice, 1586, No. 4 .

Fort. d. Med., 1883, No. 18, 1885, Nos, 11 and 24

3 Alvarez et Tavel. Recherches sur le Bacille de Lustgarten. Arch. de Phys. norm. et Path., 1885, No. 17. Klenperer. Ueber Syphilis, und Sneginabacillen. Deut. Med. Woch, 1885, S. 809. Bienstock. Fort. d. Med. 1886, S. 193. Friedländer, Ibid, S. 196. Gottstein. Ibid, 1880, S. 627 .

4 Cent. f. d. Med.Wiss., 1885, No. 33.

sort. d. Med., 1886, S.' 1 . in producing ulcerative processes in the valve of rabbits' breasts by the injection of very large quantities of the staphylococcus aureus into the circulation. In an article upon the same subject by Bramwell, ${ }^{6}$ experiments by Hare are recorded. This experimenter obtained negative results so far as the artificial production of the disease is concerned, but succeeded in obtaining from the material employed pure cultures of two organisms, one, a micrococcus resembling very strongly the staphylococcus pyogenes aureus, and the other, a short straight bacillus occurring in immense numbers. Wyssokowitsch ${ }^{7}$ and Orth $^{8}$ have taken the subject up again, but without reaching any very definite results.

\section{YELLOW FEVER.}

Freire has published a very elaborate work containing the results of his observations upon this subject and his methods. ${ }^{9} \mathrm{He}$ claims to have established that the "microbe xanthogenicus" is introduced into the system by the respiratory and digestive apparatus, that from these points of entrance it passes into the circulation and thence into all the organs of the body; it is found with equal facility in the brain, muscles, kidney, spleen, pancreas, blood, lungs, urine, bile and vomit. With regard to the blood the organism is found most largely in the capillary circulation, rather than in the larger bloodvessels. The organism is very easy of detection in the urine and bile by simply placing a drop of either of these fluids upon a slide and examining with a power of from 450 to 800 diameters ; blood must be treated with a weak solution of sulphate of soda before the orgauisms contained in it are easily visible. The period of incubation after infection is short, and the development of the organism is very rapid. The "cryptococcus xanthogenicus" appears under a diameter of 740 as minute refracting bodies, sometimes looking like black points and at other times showing a luminous spot in the center (differences of focussing). There are also yellowish masses with yellowish spots scattered about which are considered to be the scattered cells of the cryptococcus. The cells have a very rapid movement at the beginning of their development which becomes less as the cells increase in size. These cells, when mature, contain granules which are pigmented green or yellow. These finally burst through the cell-envelope and proceed to form new cells by constant increase in size. Occasionally the spores are scattered without order; sometimes they stick irregularly to the pigment, and sometimes they form regular figures, assuming shapes like a pineapple or a pear. Under cultivation the organism is found to be aërobic: it flourishes well in culture-media of bouillon, milk or gelatine solutions, forming in old cultures a yellow or even black layer upon the surface of the fluid; the ordinary temperature of the room is sufficient for its development. Methyl-violet in aqueous solution gives a very strong violet color to the cells.

Many inoculation experiments with material from yellow-fever patients - blood, urine - were practised upon animals, with the result of finding guinea pigs susceptible, whilst birds, pigeons, and chickens seemed to be refractory to the toxic effects of the organisms. The "cryptococcus xanthogenicus" was found in large

- Am.Jour. Med. Sciences, July, 1886.

7 Aus dem Path. Inst. in Göttingen.

8 Virch. Arch. Bd. 103, II.

- Doctrine Microbienne de la Fievre Janne et ses Inoculations Préventives. Rio de Janeiro. Imprimerie Nationale, 1886. 
numbers in the earth of cemeteries where persons dead of yellow fever had been buried, and in the air of yellow-fever hospitals. The attenuation of the virulent strength of the organism of yellow fever is obtained by its exposure to a low temperature $-10^{\circ}$ to $20^{\circ}$ C. for a few days - after which exposure injections into guinea pigs produces little or no effect. The virulence may be restored by keeping the culture at from $38^{\circ}$ to $50^{\circ} \mathrm{C}$; ; after a few days' exposure to this temperature, the full toxic strength returns, as proven by inoculation experiments. Acting upon these facts, Freire undertook a preventive inoculation against yellow fever with an attenuated virus.

Finding that the virulence of the "cryptococcus xanthogenicus" obtained in cold weather was less than that in warm weather, or during the time of an epidemic, he preserved cultures of the former, and used them upon man, of course being encouraged to do so by previously-completed extensive experiments upon animals. The results of these experiments seem to be favorable to his assertions, that is, that thus far, no case inoculated by him against yellow fever is as yet reported to have died of the disease.

\section{HYDROPHOBIA.}

The special interest excited in this disease by the announcement of Pasteur in regard to it has led to the endeavor, on the part of many observers, to isolate and identify the bacterium, which is in all probability the active factor in the production of the disturbance. The results thus far obtained are eminently unsatisfactory, however. Fol and Dowdeswell each think they have found a micrococcus which is the specific organism of rabies, but neither of them bring forward any evidence other than the occurrence of the bacterium in animals dead of the disease as a basis for their assertions. Pasteur himself has failed also to find anything which he is disposed to consider the "materies morbi" in this instance. Thus far there has been not only no bacterium connected with the disease, but no systematic work in confirmation of Pasteur's method of preventive inoculation has been published. Many announcements of "Pasteur Institutes" have been made in the daily press, but very little has come out with any substantial basis to it.

BACTERIOLOGICAL OBSERVATION OF WATER.

This is one of the most important of the practical applications of bacteriological science, and is being rapidly developed. A systematic observation of the limitations of chemical analysis, and the amount of evidence to be obtained in addition as to the potability of any water by the further examination by bacteriological methods, has yet to be made Such evidence would be exceedingly valuable, and it will not be long before it will be supplied. Meade Bolton ${ }^{10}$ has paid some attention to this point, concluding that it is possible for a better decision to be given as to the safety of any given specimen of water by the employment of both methods of analysis, and in certain cases, that the observation of the bacteria and the determination of their species is the only way by which approximately exact results can be obtained.

Other first-rate recent work in the same direction is to be found in the first volume of the Arbeiten das den Kais. Gesundheitsamte, 1886.
METHODS OF PRESERVING COLONIES FROM PLATECULTURES.

Garrè ${ }^{11}$ suggests that the portion of the gelatine containing the colony to be kept, be cut out, and transferred with a sterilized spatula to a slide. The preparation may then be placed in a drying apparatus, or under a glass-bell, and dried to one-half or less of its original bulk. A cover is then to be fastened on with concentrated glycerine jelly. In this way, the colony may be preserved for an almost indefinite length of time for microscopic examination and demonstration.

Plaut, ${ }^{12}$ writing upon the same subject, suggests the cutting out of the colony with fine, sterilized scissors, and its transference to a slide moistened with a very small drop of pure water. Then slight warming of the slide to settle the gelatine, but not enough to melt it, and finally, covering the whole with a cover-glass fastened by a ring of dammar-lac, the advantages claimed for this method being that the colony is not only preserved for microscopic examination, but may also be used to propagate future cultures by the simple melting of the dammar-lac with a heated needle, and the removal of the cover-glass.

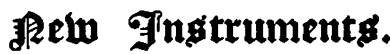

\section{A SIMPLE APPARATUS FOR WASHING OUT THE BLADDER.}

BY FRANK HOLYOKE, M.D., HOLYOKE, MASS.

The accompanying diagram illustrates an apparatus for washing out the bladder, which combines cheapness in construction, with ease and safety in use.

An eight or $t$ we l ve ounce, glass bottle, $\mathbf{A}$, has its bottom cut off; and a cork perforated by two glass tubes, is now introduced and sealed, to prevent leakage of air or water. To the glass tube, $B$, by five feet of rubber tubing, is attached a rubber catheter. To the evacuating tube, $\mathrm{C}$, is attached one foot of rubber tubing clamped by a bull-dog forcep or patent clothes-pin.

'This safety of this apparatus lies in the fact that the evacuating tube reaches within the neck of the bottle one-half inch beyond the injecting tube, so that, when held upright, there is no possible chance, while emptying the bottle through the former, for air to enter the latter.

Four pieces of cork held at regular intervals by a narrow rubber band prevent the bottle from rolling off the table, while the patient - either standing or seated introduces the catheter; upon the entrance of which within the bladder the bottle is held as represented and brought below the level of the bladder. The

11 Fort. d. Med., 1886, S. 392.
12 Fort. d. Med., 1886, S. 419.

rnal as published by 